\title{
Development and validation of a tool to assess the physical and social environment associated with physical activity among adults in Sri Lanka
}

\author{
Shreenika H De Silva Weliange ${ }^{1 *}$, Dulitha Fernando ${ }^{2}$ and Jagath Gunatilake ${ }^{3}$
}

\begin{abstract}
Background: Environmental characteristics are known to be associated with patterns of physical activity (PA). Although several validated tools exist, to measure the environment characteristics, these instruments are not necessarily suitable for application in all settings especially in a developing country. This study was carried out to develop and validate an instrument named the "Physical And Social Environment Scale - PASES" to assess the physical and social environmental factors associated with PA. This will enable identification of various physical and social environmental factors affecting PA in Sri Lanka, which will help in the development of more tailored intervention strategies for promoting higher PA levels in Sri Lanka.

Methods: The PASES was developed using a scientific approach of defining the construct, item generation, analysis of content of items and item reduction. Both qualitative and quantitative methods of key informant interviews, in-depth interviews and rating of the items generated by experts were conducted. A cross sectional survey among 180 adults was carried out to assess the factor structure through principal component analysis. Another cross sectional survey among a different group of 180 adults was carried out to assess the construct validity through confirmatory factor analysis. Reliability was assessed with test re-test reliability and internal consistency using Spearman $r$ and Cronbach's alpha respectively.

Results: Thirty six items were selected after the expert ratings and were developed into interviewer administered questions. Exploration of factor structure of the 34 items which were factorable through principal component analysis with Quartimax rotation extracted 8 factors. The 34 item instrument was assessed for construct validity with confirmatory factor analysis which confirmed an 8 factor model $\left(x^{2}=339.9, \mathrm{GFI}=0.90\right)$. The identified factors were infrastructure for walking, aesthetics and facilities for cycling, vehicular traffic safety, access and connectivity, recreational facilities for PA, safety, social cohesion and social acceptance of PA with the two non-factorable factors, residential density and land use mix. The PASES also showed good test re-test reliability and a moderate level of internal consistency.
\end{abstract}

Conclusions: The PASES is a valid and reliable tool which could be used to assess the physical and social environment associated with PA in Sri Lanka.

Keywords: Physical and social environment, Physical activity, Development of a tool

\footnotetext{
* Correspondence: shreenika73@yahoo.co.uk

'Department of Community Medicine, University of Colombo, Colombo,

Sri Lanka

Full list of author information is available at the end of the article
} 


\section{Background}

The burden of mortality, morbidity and disability due to non-communicable diseases (NCDs) is high and is increasing in the developing countries [1]. Physical inactivity is identified as the fourth leading risk factor for mortality due to NCDs and contributes to $6 \%$ of deaths globally [2]. In 2001, $71 \%$ of all deaths in Sri Lanka were due to chronic NCDs and chronic NCD mortality is reported to be $20-30 \%$ higher in Sri Lanka than in many developed countries [3]. According to the Annual Health Statistics, coronary heart disease was the leading cause of hospital deaths in Sri Lanka since 1997 [4]. The World Health Survey data collected in 2002-2003 revealed that in Sri Lanka $7.3 \%$ of the males and $13.8 \%$ of the females were physically inactive [5].

Being physically active is influenced by both the physical and social environment [6,7] and is best explained through a socio-ecological model of health related behaviours. Many studies have recognized that environmental factors have a significant role in promoting PA among adults [8-13] and changing behaviours in an entire community [14]. Literature identifies some common physical (built) environment factors associated with PA. They are landuse patterns, transport systems, urban design, green space, availability of pavements, heavy traffic, street lights, unattended dogs, enjoyable scenery, high levels of crime, and easy access to recreation and retail shops $[15,16]$. Income, equity, culture and social support are identified in literature as elements in the social environment that influences participation in PA $[17,18]$.

Considering the apparent importance of the environment for PA, there is limited information in the literature on how best to measure various aspects of the environment. Evidence on the associations between the physical environment and PA behaviour is derived mostly from self-reported data on individuals' perceptions of their environments [19]. Observational methods is another form where individuals using checklists, rates the environment. The introduction of geographic information systems into PA research has revolutionised the measurement of the physical environment, and is still in its early stages [20]. Two major types of PA that have been studied in relation to the environment are the recreational PA and PA through non motorized transportationwalking/cycling. An accepted method of measuring the perceived physical environment is through population based studies and surveillance systems [21]. Individual responses can then be aggregated to identify patterns in environment characteristics. Thereafter, it is possible to determine the association between the design characteristics of the environment and behaviour [22]. There are different tools developed for assessment of environment characteristics that are related to different types of PA.
Abbreviated Neighbourhood Environment Walkability Scale (ANEWS) and the International Physical Activity Questionnaire- environmental (IPAQ-e) are two tools that have been extensively used. ANEWS, a 98 question, selfadministered instrument to determine the perception of neighbourhood design features hypothesised to be related to PA [23] was developed in San Diego. It consists of six subscales of land use mix-access, street connectivity, infrastructure for walking/cycling, aesthetics, traffic safety and crime safety [24]. IPAQ-e is a 17 item, 4 factor tool which is considered to be relevant to all countries regardless of the stage of economic development [25], with the factors being the degree of urbanisation, traffic intensity, aesthetics and opportunity and fear of crime [26]. There are several other tools which have been developed in America, Europe and Australia to measure the environment associated with PA. All the above mentioned instruments are known to have an average interviewer administration time of 24-30 minutes [23]. Although tools to assess physical and social environment associated with PA in adults have been developed, validated and utilized extensively in developed countries, South Asia and particularly Sri Lanka lacks a validated tool to assess physical and social environment associated with PA. The purpose of conducting this study was to develop and pilot a tool to assess the physical and social environment associated with PA among adults in the district of Colombo and to assess the construct validity and reliability of it.

\section{Methods}

\section{Study setting}

This study was conducted in the district of Colombo in the western province of Sri Lanka which encompasses the economic capital of Sri Lanka. It extends over an area of 696 square kilometers with a population of $2,390,871$ and a population density of 3330 persons per square kilometre [27].

\section{Arriving at a definition for the physical and social environment associated with PA}

Physical and social environment associated with PA was defined initially by considering the definitions given by different authors through a literature search carried out on medical sciences, urban development and design, transport studies and social sciences publications. These definitions were then reviewed with several experts in the fields of community medicine, environment studies, urban planning and architecture, engineering including transport engineering, sociology, health promotion, sports medicine and psychology. The most suitable definition was formulated based on the outcome of the above process. 


\section{Item generation}

Item generation was initiated with a literature review which was conducted to identify all aspects of the physical and social environment relevant to PA behaviour among adults in urban and rural communities. Experts who had developed similar questionnaires in the developed countries were contacted. After reviewing several different instruments, all the items used were identified, listed and adopted in a culturally acceptable manner. Thereafter key informant interviews were conducted with the above mentioned experts to generate items. A purposive sampling method was adopted to select the key informants. This was complimented with in-depth interviews with the general public between the ages of 20-59 years living in the Colombo district. Fifteen indepth interviews were carried out using an interviewer guide. Notes were taken after prior permission. Transcripts of the interviews were made and were coded to identify the main items.

\section{Analysis of the content of items and item reduction}

The items were rated by the experts on a five-point scale (1- least important and 5- most important). An item with a mean score of 3 or more was considered for inclusion in the next round. Items were finalized after two iterations of independent ratings by experts.

\section{Formulating draft instrument to measure physical and social environment associated with PA and translation}

An interviewer administered questionnaire was developed conferring to the measures described by Streiner and Norman [28]. A direct continuous judgment scale with 5 response choices was adopted. The scoring was a simple scoring with scores ranging from 1 to 5 . The lowest value 1 indicated the least likelihood of having a conducive environment for PA whereas the highest value 5 indicated the most likelihood of having a conducive environment for PA. The question on residential density and distance to facilities was assessed differently according to the consensus of experts.

The draft instrument developed in English was independently translated to Sinhala by two translators, with a high level of proficiency in English and Sinhala. This was back translated to English and was checked with the original English version and necessary modifications were carried out.

\section{Finalising the PASES with exploratory factor analysis}

In order to assess how the selected 36 items were related to each other, and to see if there was a need for further reduction of items, exploratory factor analysis was carried out using the 34 factorable items. Two items, residential density and land use mix were not included, for the reason that the response categories of these two items were not appropriate to be included in exploratory factor analysis.

Adults aged 20-59 years living in the Colombo district for a period of not less than 6 months were invited to assess their environment using the developed instrument. Institutionalised adults, adults with any physical disability preventing engagement in PA, pregnant females up to a postpartum period of 3 months, adults with severe psychiatric illness and adult visitors to the area were excluded from the study. One hundred and eighty people were interviewed which is more than the recommendation (5 participants per item in the tool) for the sample size in multivariate analysis [29]. A trained interviewer visited the households during weekends to collect data. Data collection was done after information on the purpose of the study was given and written consent was obtained from the selected participant.

Principal Component Analysis (PCA) was applied using Statistical Package for Social Sciences version 17 to explore the factor structure. After assessing the sampling adequacy and factorability, those factors with eigen values of more than one were selected. Scree plots were examined and factors were rotated to optimize the interpretability of the scale. A pre-test was carried out prior to finalizing the instrument -PASES. The PASES is shown as Additional file 1.

\section{Confirmatory factor analysis}

Confirmatory factor analysis (CFA) was carried out to assess the extent to which the underlying eight factor model was replicated in a new data set. Although many factors including size of the model, distribution of variables, amount of missing data, reliability of the variables and strength of the relationship among variables affect the sample size [30], a recommended sample size for CFA is more than 5 times the number of items in the instrument [29]. The instrument was administered to a different group of 180 adults between the ages of 20-59 years living in the Colombo district for a period of not less than 6 months with exclusion criteria similar as above. Data collection too was similar to the data collection procedure for PCA. Data on basic socio demographic and PA were also obtained.

The 34 factorable items were deployed for CFA using LISREL 8.8. after ensuring that the statistical assumptions required for CFA was met. Normality of the data was assessed by inspecting item histograms and calculating the standardized skewness and kurtosis. Multicollinearity was explored through bivariate correlations between the items.

Considering the non-normal distribution of the items of PASES and according to the recommendations offered in LISREL 8.8 [31], Robust Maximum Likelihood (RML) estimation method with the Satorra-Bentler scaled 
chi-square for fit estimation was used for the CFA. The CFA was performed on the covariance matrix of the items of the PASES. Assessment of the appropriateness of the models was based on several fit indices. The absolute fit indices considered were the $X^{2}$ with degrees of freedom (df) and the P value, Goodness of fit index (GFI) and the standardized root mean square residual (SRMR). The Parsimony correlations that were assessed were the root mean square error of approximation (RMSEA). Comparative fit indices that were used were the comparative fit index (CFI) and the Non-normed Fit Index (NNFI) [30]. The judgments about how well the model fit data in this study were made on the basis of RMSEA $<0.05$, SRMR $<0.08$ CFI $>0.90$ and NNFI $>0.90$ which have been adopted when assessing model fit in similar situations [32]. The reliability of the instrument was assessed by test re-test method, by administering the same questionnaire to 50 randomly selected participants after a two week interval. Internal consistency which is a measure of "item homogeneity" was assessed by calculating Cronbach's Alpha for each sub-division score of the PASES.

The Ethics Review Committee of Faculty of Medicine, University of Colombo approved the study protocol (reference number EC-09-084) and data collection was carried out after obtaining informed written consent from each participant.

\section{Results}

\section{Arriving at a definition for the physical and social} environment associated with PA.

For the purpose of this study, physical and social environment associated with PA was defined as the "external context consisting of the characteristics of the natural and built environment and the characteristics of the people in the neighbourhood which influences participation in PA".

\section{Item generation}

The literature review, key informant interviews and indepth interviews generated 80 items which was reduced to 36 after independent rating by the experts.

\section{Finalising the PASES with exploratory factor analysis}

The sample for the survey to carry out exploratory factor analysis consisted of, $52 \%$ males and $48 \%$ females. Twenty eight percent of the participants were educated up to G.C.E. O/L or less, while the majority had education above G.C.E. O/L. Majority (84\%) of the participants were employed. The sampling adequacy was assessed through inspection of the inter correlation matrix which showed that there were many correlations that were more than 0.3. In the anti-image correlation matrix the coefficients were well above the accepted level of 0.5 . Factorability of the data assessed by Bartlett's test of sphericity, was significant at $\mathrm{p}<0.01$. The Kaiser- Meyer- Olkin measure was
0.742 which was well above the requirement of 0.6. The items which grouped together were identified as latent factors and were considered relevant only if its eigen value exceeded 1.0. PCA with Quartimax rotation technique gave the best results. Table 1 shows the factor coefficients of individual items after rotation. Eigen values ranged from 7.18 to 1.16 . All of the items loaded well to the factors (factor loading >0.4), requiring no further reduction of items. This method initially identified 9 latent factors with one factor retaining only one item. However, as this item also cross loaded with another factor with factor loading of $>0.4$ and as the cross loading appeared sensible the 8 factor model was selected as the final model after PCA. The factors identified were named as follows:

1 Infrastructure for walking

2 Aesthetics and facilities for cycling

3 Vehicular traffic safety

4. Access and connectivity

5 Recreational facilities for PA

6 Safety

7 Social cohesion

8 Social acceptance of PA

The PASES was validated using CFA for Sri Lanka after the pre-test.

\section{Confirmatory factor analysis}

The response rate of the cross sectional survey was $100 \%$. The socio demographic characteristics of the sample of 180 adults are given in Table 2. The standardised skewness and kurtosis was calculated by dividing the unstandardised skew or kurtosis by its corresponding standard error, which is interpreted as the $\mathrm{z}$ test of skew or kurtosis [33]. The ratios greater than 1.96 and have a $\mathrm{p}$ value of 0.05 , indicate significant skew or kurtosis. The values show that in this sample 22 items had high standard skewness while 10 items had high standard kurtosis. Items in the model should not be highly correlated or perfectly correlated because multicollinearity hinders the interpretability of the results. When the bivariate correlations between the items were examined, although the highest correlation observed between two items was $0.78,95 \%$ of the correlations were less than 0.06 showing that no two items were highly correlated or perfectly correlated. Therefore several models were evaluated using RML method and were assessed for fit indices.

Initially a 2 factor model was tested where all items in the physical environment were grouped to one and those of the social environment were grouped to another. This model failed to converge and did not show acceptable fit. Thereafter a 6 factor model was tested with 'infrastructure for walking' and 'access and connectivity' combined as one 
Table 1 Item distribution in PCA (the highest correlation coefficient for the item is in bold)

\begin{tabular}{|c|c|c|c|c|c|c|c|c|}
\hline Items & $\begin{array}{l}\text { Infrastructure } \\
\text { for walking }\end{array}$ & $\begin{array}{l}\text { Aesthetics } \\
\text { and facilities } \\
\text { for cycling }\end{array}$ & $\begin{array}{l}\text { Vehicular } \\
\text { traffic safety }\end{array}$ & $\begin{array}{l}\text { Access and } \\
\text { connectivity }\end{array}$ & $\begin{array}{l}\text { Recreational } \\
\text { facilities for } \\
\text { physical activity }\end{array}$ & Safety & $\begin{array}{l}\text { Social } \\
\text { cohesion }\end{array}$ & $\begin{array}{l}\text { Social acceptance } \\
\text { of physical } \\
\text { activity }\end{array}$ \\
\hline $\begin{array}{l}\text { Sidewalks in the main } \\
\text { street }\end{array}$ & 0.788 & -0.076 & -0.140 & 0.095 & 0.015 & -0.240 & 0.007 & 0.132 \\
\hline $\begin{array}{l}\text { Grass/sand strip in the } \\
\text { by roads }\end{array}$ & 0.573 & 0.350 & -0.050 & -0.084 & 0.098 & -0.316 & -0.020 & 0.099 \\
\hline sidewalks not obstructed & 0.726 & 0.183 & 0.185 & 0.145 & 0.031 & -0.010 & 0.131 & -0.163 \\
\hline sidewalks free of hazards & 0.666 & 0.207 & 0.101 & 0.153 & 0.076 & 0.315 & -0.032 & 0.007 \\
\hline Special lanes to cycle & 0.203 & 0.789 & 0.083 & 0.043 & 0.046 & -0.006 & -0.088 & 0.040 \\
\hline Shade in the pathways & -0.001 & 0.807 & 0.063 & 0.204 & 0.066 & 0.179 & 0.020 & 0.088 \\
\hline $\begin{array}{l}\text { Trees in the } \\
\text { neighbourhood }\end{array}$ & 0.208 & 0.508 & 0.106 & 0.383 & 0.050 & 0.066 & -0.232 & 0.045 \\
\hline $\begin{array}{l}\text { Interesting/pleasant } \\
\text { things to look in the } \\
\text { neighbourhood }\end{array}$ & -0.118 & 0.589 & 0.198 & 0.189 & 0.086 & 0.209 & 0.129 & 0.003 \\
\hline $\begin{array}{l}\text { Neighbourhood free of } \\
\text { dust and fumes }\end{array}$ & 0.206 & 0.147 & 0.560 & 0.360 & -0.072 & -0.092 & 0.157 & -0.112 \\
\hline Low movement of traffic & 0.050 & 0.247 & 0.697 & 0.313 & 0.150 & 0.124 & 0.052 & 0.114 \\
\hline Low speed of vehicles & -0.116 & 0.223 & 0.645 & 0.328 & 0.105 & 0.053 & 0.323 & 0.041 \\
\hline Less road traffic accidents & 0.092 & 0.078 & 0.560 & 0.183 & 0.051 & 0.122 & 0.330 & -0.060 \\
\hline $\begin{array}{l}\text { Amenities are easily } \\
\text { accessible }\end{array}$ & 0.222 & 0.046 & 0.215 & 0.491 & 0.123 & -0.006 & 0.087 & 0.202 \\
\hline $\begin{array}{l}\text { Short distance to main } \\
\text { road }\end{array}$ & -0.203 & 0.246 & -0.314 & 0.514 & 0.115 & -0.115 & 0.031 & 0.039 \\
\hline Short distance to transport & -0.015 & 0.180 & 0.094 & 0.672 & -0.019 & -0.228 & 0.113 & 0.358 \\
\hline Terrain is good for PA & -0.045 & 0.013 & 0.127 & 0.575 & 0.356 & -0.156 & 0.154 & 0.092 \\
\hline $\begin{array}{l}\text { Presence of pedestrian } \\
\text { crossing, signals and } \\
\text { overhead bridges }\end{array}$ & 0.118 & -0.053 & 0.116 & 0.739 & 0.005 & 0.033 & 0.322 & -0.201 \\
\hline $\begin{array}{l}\text { Alternative routes to get } \\
\text { from place to place }\end{array}$ & 0.013 & 0.054 & -0.080 & 0.638 & -0.013 & -0.007 & 0.228 & 0.164 \\
\hline Recreational centers for PA & 0.040 & 0.000 & -0.003 & 0.228 & 0.573 & 0.390 & -0.115 & 0.390 \\
\hline Public spaces for recreation & 0.138 & 0.131 & 0.024 & 0.104 & 0.474 & 0.513 & -0.048 & 0.174 \\
\hline $\begin{array}{l}\text { Easy accessibility of } \\
\text { recreation places }\end{array}$ & 0.070 & 0.165 & 0.061 & -0.102 & 0.750 & -0.080 & 0.020 & -0.047 \\
\hline Low crime rate & 0.201 & 0.063 & 0.029 & 0.282 & -0.109 & 0.616 & 0.201 & -0.074 \\
\hline Well lit roads & -0.117 & 0.182 & 0.205 & -0.090 & -0.005 & 0.669 & 0.187 & -0.217 \\
\hline $\begin{array}{l}\text { Neighbourhood free of } \\
\text { stray animals }\end{array}$ & 0.122 & -0.003 & 0.110 & 0.318 & -0.134 & 0.538 & 0.265 & -0.040 \\
\hline $\begin{array}{l}\text { Good interaction between } \\
\text { people in the } \\
\text { neighbourhood }\end{array}$ & 0.021 & 0.138 & 0.060 & -0.016 & -0.048 & 0.385 & 0.624 & 0.301 \\
\hline $\begin{array}{l}\text { Harmony between people } \\
\text { in the neighbourhood }\end{array}$ & 0.134 & -0.148 & 0.081 & 0.145 & -0.084 & 0.047 & 0.801 & 0.039 \\
\hline Respect each other & -0.082 & 0.067 & -0.018 & 0.179 & 0.041 & 0.150 & 0.870 & 0.057 \\
\hline $\begin{array}{l}\text { Free of social disorder/ } \\
\text { disputes }\end{array}$ & -0.062 & 0.086 & 0.114 & 0.135 & -0.072 & 0.064 & 0.824 & 0.026 \\
\hline $\begin{array}{l}\text { Helpful people in the } \\
\text { neighbourhood }\end{array}$ & 0.029 & -0.087 & -0.097 & 0.192 & 0.055 & -0.185 & 0.862 & 0.044 \\
\hline $\begin{array}{l}\text { Trustworthy people in } \\
\text { the neighbourhood }\end{array}$ & 0.081 & -0.100 & 0.054 & 0.167 & 0.154 & -0.389 & 0.696 & 0.262 \\
\hline
\end{tabular}


Table 1 Item distribution in PCA (the highest correlation coefficient for the item is in bold) (Continued)

\begin{tabular}{|c|c|c|c|c|c|c|c|c|}
\hline $\begin{array}{l}\text { People in the } \\
\text { neighbourhood } \\
\text { encourage to be active }\end{array}$ & -0.024 & 0.059 & -0.042 & 0.018 & -0.066 & 0.020 & 0.288 & 0.687 \\
\hline $\begin{array}{l}\text { People in the } \\
\text { neighbourhood are } \\
\text { physically active }\end{array}$ & 0.042 & -0.001 & 0.106 & 0.072 & -0.090 & -0.060 & 0.095 & 0.854 \\
\hline $\begin{array}{l}\text { Social acceptance for } \\
\text { being active for day } \\
\text { to day activities }\end{array}$ & -0.052 & 0.010 & 0.063 & -0.006 & 0.005 & -0.096 & 0.068 & 0.870 \\
\hline $\begin{array}{l}\text { Social acceptance for } \\
\text { Walking, exercising and } \\
\text { recreational sport }\end{array}$ & -0.020 & 0.103 & -0.114 & 0.006 & 0.260 & 0.010 & 0.064 & 0.741 \\
\hline
\end{tabular}

factor, and vehicular 'traffic safety' and 'safety' combined as another factor with rest of the factors according to the factors identified by PCA. This model showed acceptable model fit with a chi square value of $364.41(\mathrm{df}=512)$.

A seven factor model was also tested with item of 'infrastructure for walking' and 'access and connectivity' combined as one factor. This model showed an acceptable fit with a chi square value of $360(\mathrm{df}=506)$. Another

Table 2 Frequency distribution of selected socio-demographic characteristics of the participants ( $n=180$ )

\begin{tabular}{|c|c|c|}
\hline Demographic characteristic & Frequency & Percentage \\
\hline \multicolumn{3}{|l|}{ Age category (years) } \\
\hline $20-29$ & 40 & 22.2 \\
\hline 30-39 & 49 & 27.2 \\
\hline $40-49$ & 43 & 23.9 \\
\hline $50-59$ & 48 & 26.7 \\
\hline \multicolumn{3}{|l|}{ Sex } \\
\hline Male & 78 & 42.8 \\
\hline Female & 102 & 57.2 \\
\hline \multicolumn{3}{|l|}{ Ethnicity } \\
\hline Sinhalese & 177 & 98.3 \\
\hline Other & 03 & 01.7 \\
\hline \multicolumn{3}{|l|}{ Religion } \\
\hline Buddhism & 177 & 98.3 \\
\hline Other & 03 & 01.7 \\
\hline \multicolumn{3}{|l|}{ Monthly family income in Rupees } \\
\hline 10,000 or less & 49 & 27.2 \\
\hline $10,001-20,000$ & 90 & 50.0 \\
\hline $20,001-30,000$ & 25 & 13.9 \\
\hline $30,001-40,000$ & 04 & 02.2 \\
\hline More than 40,000 & 12 & 06.7 \\
\hline \multicolumn{3}{|c|}{$\begin{array}{l}\text { Presence of a long standing illness } \\
\text { of }>6 \text { months }\end{array}$} \\
\hline Yes & 40 & 22.2 \\
\hline No & 140 & 77.8 \\
\hline
\end{tabular}

7 factor model with 'social cohesion' and 'social acceptance of PA' combined together as one factor increased the chi square value to $397(\mathrm{df}=506)$. A 8 factor model was tested according to factors derived from PCA. This model showed a better fit with a chi square value of 339.94 ( $\mathrm{df}=499)$, $\mathrm{p}$ value of 1.00 , GFI of 0.90 , and RMSEA of 0.001 . The summary findings of the model fit statistics of different models are shown in the Table 3. Therefore the 8 factor model was accepted as the best fit model.

The results of the test re-test reliability assessed through Spearman's r coefficients are given in Table 4. The correlation scores ranged from 0.628-0.916. The lowest correlation 0.628 was in the domains of aesthetics and recreational facility. The internal consistency measured by Chronbach's Alpha for the physical environment was 0.49 , while for the social environment it was 0.82 . Both values were significant at $\mathrm{p}<0.01$ level.

\section{Discussion}

An active lifestyle is a complex behavioural process that is influenced by various factors of which environmental factors are well recognized $[19,34,35]$. This study was designed to develop a valid and reliable tool to assess the physical and social environment associated with PA in the Colombo district, considering the socio-ecological model for PA behaviour.

The procedure adopted to develop PASES was similar to the procedures used for the development of many other study instruments to assess the physical and social environment for PA in other countries [36,37]. The steps included: defining the construct, item generation, analysis of the content of items and item reduction, field testing and validation of the developed instrument [38,39]. Both the quantitative and qualitative research methods provided comprehensive methodologies for exploration of ideas [38], including key informant interviews and in-depth interviews [28]. Item reduction initially was through a simple and non statistical method where a group of experts rated the importance of each item for the appropriateness of the item to the main construct independently. 
Table 3 Summary of model fit statistics of the PASES

\begin{tabular}{|c|c|c|c|c|c|c|c|c|}
\hline \multirow[t]{2}{*}{ Model } & \multicolumn{5}{|c|}{ Absolute fit indices } & \multicolumn{2}{|c|}{ Comparative fit } & \multirow{2}{*}{$\begin{array}{l}\text { Parsimony correlation } \\
\text { RMSEA }\end{array}$} \\
\hline & $x^{2}$ & df & $\mathbf{p}$ & GFI & SRMR & NNFI & CFI & \\
\hline 6 factor model & 364.41 & 512 & 1.00 & 0.89 & 0.068 & 1.20 & 1.00 & 0.001 \\
\hline 7 factor model (a) & 360.00 & 506 & 1.00 & 0.89 & 0.068 & 1.20 & 1.00 & 0.001 \\
\hline 7 factor model (b) & 397.00 & 506 & 0.99 & 0.88 & 0.070 & 1.18 & 1.00 & 0.001 \\
\hline 8 factor model & 339.94 & 499 & 1.00 & 0.90 & 0.066 & 1.21 & 1.00 & 0.001 \\
\hline
\end{tabular}

$\mathrm{X} 2=$ Chi-square test

$\mathrm{p}=(>0.05$ desired $)$.

$\mathrm{GFI}=$ goodness of fit index ( $>0.9$ desired).

SRMR $=$ standardized root mean square residual $(<0.08$ desired).

$\mathrm{NNFI}=$ Non-normed fit index ( $>0.9$ desired).

$\mathrm{CFI}=$ comparative fit index $(>0.9$ desired $)$.

RMSEA $=$ root mean square error of approximation $(<0.05$ desired).

This method facilitated uninfluenced views of each expert as they did not meet each other [40]. According to guidelines of developing new instruments [38], PCA was carried out on a data set that was gathered by administering the translated items to a group of people considered to be similar to the population that the developed instrument was intended to be used [41]. PCA explored the factor structure of the scale and showed that all the items loaded well (factor loadings $>0.4$ ) to 8 factors. Hence, no further reduction of data was required through $\mathrm{PCA}$.

CFA on the multi-dimensional construct showed adequate model fit despite emergence of 8 latent factors for the 34 items. Although the PASES was a 8 factor model, the ANEWS had a 6 factor structure after CFA [42] and the IPAQ-e module had 4 factors after PCA [26]. This was expected as some of the items in the three instruments differed. The PASES had two social factors while the ANEWS and IPAQ-e had no social factors.

In the reliability assessment, the Chronbach's Alpha for physical environment sub-division was 0.487 and for the social environment subdivision was 0.823 , indicating a moderate reliability. However, the reliability findings of the present study are comparable with most of reliability tests carried out on environment assessment tools $[43,44]$. The test re-test reliability in the present

Table 4 Test re-test reliability of the mean scores of 8 factors of the PASES

\begin{tabular}{ll}
\hline Factors of PASES & Correlation coefficient \\
\hline Infrastructure for walking & 0.746 \\
Aesthetics and facilities for cycling & 0.628 \\
Vehicular traffic safety & 0.789 \\
Access and connectivity & 0.812 \\
Recreational facilities for PA & 0.636 \\
Safety & 0.847 \\
Social cohesion & 0.916 \\
Acceptance of PA & 0.834 \\
\hline
\end{tabular}

study was between 0.6-0.9, confirming the ability of the PASES to generate reproducible results.

The factors identified and validated were comparable with other tools developed in the USA and Europe, with some variation. Infrastructure for walking has been a common factor identified in many instruments [23] and have shown to be associated with the total PA and walking both for leisure and transport [13,45]. Items relating to access and connectivity and the infrastructure for walking were seen to load together as 'degree of urbanisation' [26] in the IPAQ-e module but the PASES identified it separately as in the ANEWS [24]. Aesthetics and facilities for cycling were identified as one factor in the PASES as the perception of the beauty of the environment and facilities for cycling were perceived in a similar manner in the Sri Lankan setting. However aesthetics were a separate factor in both the ANEWS and IPAQ-e tools. Vehicular traffic safety, and safety which are important factors in the environment, were identified in the newly developed and validated tool, with additional factor of 'recreational facilities for PA'. Two social factors, namely social cohesion and social acceptance of PA were identified as important and were incorporated to the PASES. Although not factor analysed 'residential density' and 'land use mix diversity' were components of the newly developed tool PASES. These two components measure proximity, indicating how close different travel destinations are to one another in space. Density indicates the concentration of people, dwelling units or households [45] and mixture of use of land refers to the spatial placement of different types of land uses (industrial, residential, commercial). The factors identified in the PASES were in some ways similar to other environmental assessment tools with some variation which might reflect the Asian setting.

However, it should be noted that findings of factor analysis assessments are often sample specific [46] and generalizability of these findings to other populations would depend on their similarity to this study population. The specific "aspects" that could be studied may 
vary from within and between countries. This study instrument could be used to assess the physical and environmental factors associated with PA in South Asia and other parts of Sri Lanka after testing for reliability and validity in that particular setting.

\section{Conclusion}

A valid and reliable tool to assess the physical and social environment associated with PA was developed in Sri Lanka. This work contributes to a set of tools which can be used by researchers to identify the current perception of the environment for participation in PA by the community and to assess any change in the perception with interventions and with time.

\section{Additional file}

Additional file 1: Physical and Social Environment Scale-PASES.

\section{Abbreviations}

ANEWS: Abbreviated neighbourhood environment walkability scale; CFA: Confirmatory factor analysis; CFI: Comparative fit index; GFI: Goodness of fit index; IPAQ-e: International physical activity questionnaire environment; NCD: Non communicable disease; NNFI: Non-normed fit index; PA: Physical Activity; PASES: Physical and social environment scale; RMSEA: Root mean square error of approximation; SRMR: Standardized root mean square residual.

\section{Competing interests}

The authors declare that they have no competing interests.

\section{Authors' contributions}

SDW - made contribution to the design, planning the study, literature search, acquisition of data, analysis and interpretation of the results, drafting the manuscript and revising it critically and has given final approval of the version to be published. DF - contributed to the planning of the study, assisted in planning data analysis, drawing conclusions and in revising it critically for important intellectual content the preparation of the research paper and has given final approval of the version to be published. JG contributed to the planning of the study, planning data analysis, drawing conclusions and in revising it critically for important intellectual content the preparation of the research paper and has given final approval of the version to be published.

\section{Authors' information}

SDW is a lecturer in the Department of Community Medicine, University of Colombo. DF is the Emeritus Professor of Community Medicine, University of Colombo and JF is a senior lecturer in the Department of Geology, University of Peradeniya and is the coordinator, Msc programme in GIS and Remote Sensing at the University of Peradeniya Sri Lanka.

\section{Acknowledgements}

Authors wish to thank the administrators of the district of Colombo and the participants of the study for their support and participation. This research was funded by the University Grants Commission of Sri Lanka.

\section{Author details}

'Department of Community Medicine, University of Colombo, Colombo, Sri Lanka. ${ }^{2}$ Emeritus Professor of Community Medicine, University of Colombo, Colombo, Sri Lanka. ${ }^{3}$ Department of Geology, University of Peradeniya, Peradeniya, Sri Lanka.

Received: 9 January 2014 Accepted: 24 April 2014

Published: 3 May 2014

\section{References}

1. World Health Organisation: Global strategy on diet, physical activity and health; 2004 [http://www.who.int/dietphysicalactivity/strategy/eb11344/ strategy_english_web.pdf]

2. World Health Organisation: Global status report on non-communicable diseases 2010. [http://www.who.int/nmh/publications/ncd_report_full_en.pdf]

3. World Bank: Sri Lanka-Addressing needs of an aging population. [http://wwwwds.worldbank.org/external/default/WDSContentServer/WDSP/B/2010/10/29/ 000334955_20101029044915/Rendered/PDF/

575630WPOBox351DSOSriLanka01PUBLIC1.pdf

4. Ministry of Healthcare and Nutrition Sri Lanka: Annual Health Statistics. Colombo: Ministry of Healthcare and Nutrition; 2003.

5. Guthold R, Ono T, Strong KL, Chatterji S, Morabia A: Worldwide variability in physical inactivity: a 51- country survey. Am J Prev Med 2008, 34(6):486-494.

6. Sallis JF, Cervero RB, Ascher W, Henderson KA, Kraft MK, Kerr J: An ecological approach to creating active living communities. Annu Rev Publ Health 2006, 27:297-322

7. Stokols D: Translating social ecological theory into guidelines for community health promotion. Am J Health Promot 1996, 10:282-298.

8. Troped PJ, Saunders RP, Pate RR, Reininger B, Ureda JR, Thompson SJ: Associations between self-reported and objective physical environmental factors and use of a community rail-trail. Prev Med 2001, 32(2):191-200.

9. Handy SL: Critical assessment of the literature on the relationships among transportation, land use, and physical activity, TRB special report 282. Washington, DC: Transportation Research Board and Institute of Medicine Committee on Physical Activity, Health, Transportation, and Land Use; 2005.

10. Owen N, Humpel N, Leslie E, Bauman A, Sallis J: Understanding environmental influences on walking: review and research agenda. Am J Prev Med 2004, 27:67-76.

11. Owen N, Leslie E, Salmon J, Fotheringham M: Environmental determinants of physical activity and sedentary behavior. Exerc Sports Sci Rev 2000, 28:153-158.

12. Saelens B, Sallis J, Frank L: Environmental correlates of walking and cycling: findings from the transportation, urban design and planning literatures. Ann Behav Med 2003, 25:80-91.

13. Duncan MJ, Spence JC, Mummery WK: Perceived environment and physical activity: a meta-analysis of selected environmental characteristics. Int $\lrcorner$ Behav Nutr Phys Activ 2005, 2:11

14. Sallis JF, Owen N: Physical activity and behavioral medicine. Thousand Oaks, CA: Sage Publications Inc; 1999

15. Frank LD, Engelke P: Multiple impacts of the built environment on public health: walkable places and the exposure to air pollution. Int Reg Sci Rev 2005, 28(2):193-216

16. Addy CL, Wilson DK, Kirtland KA, Ainsworth BE, Sharpe P, Kimsey D: Associations of perceived social and physical environmental supports with physical activity and walking behaviour. Am J Publ Health 2004, 94(3):440-443.

17. Ishii K, Shibata A, Oka K: Environmental, psychological, and social influences on physical activity among Japanese adults: structural equation modeling analysis. Int J Behav Nutr Phys Activ 2010, 7:61.

18. Stahl T, Rütten A, Nutbeam D, Bauman A, Kannas L, Abel T, Lüschen $G$, Rodríguez Diaz JA, Vinck J, van der Zee J: The importance of the social environment for physically active lifestyle-results from an international study. Soc Sci Med 2001, 52(1):1-10.

19. Humpel N, Owen N, Leslie E: Environmental factors associated with adults' participation in physical activity: a review. Am J Prev Med 2002, 22(3):188-199.

20. SallisJ F: Measuring physical activity environments-a brief history. Am J Prev Med 2009, 36(45):86-92.

21. Baker EA, Brennan LK, Brownson R, Houseman RA: Measuring the determinants of physical activity in the community: current and future directions. Res Q Exerc Sport 2000, 71(2S):146-158.

22. Brownson RC, Baker EA, Housemann RA, Brennan LK, Bacak SJ: Environmental and policy determinants of physical activity in the United States. Am J Publ Health 2001, 91(12):1995-2003.

23. Brownson RC, Chang JJ, Eyler AA, Ainsworth BE, Kirtland KA, Saelens BE, Sallis JF: Measuring the environment for friendliness towards physical activity: a comparison of the reliability of 3 questionnaires. Am J Publ Health 2004, 94(3):473-483.

24. Cerin E, Saelens BE, Sallis JF, Frank LD: Neighbourhood environment walkability scale: validity and development of a short form. Med SCi Sports Exerc 2006, 38(9):1682-1691. 
25. Adegoke BOA, Oyeyemi AY, Fatudimu BM: Test-retest reliability of IPAQ environmental-module in an African population. International Journal of Behavioral Nutrition and Physical Activity 2008, 5:38-44.

26. Bergman P, Grjibovski AM, Hagströmer M, Sallis JF, Sjöström M: The association between health enhancing physical activity and neighbourhood environment among Swedish adults - a populationbased cross-sectional study. Int I Behav Nutr Phys Activ 2009, 6:8.

27. Department of Census and Statistics Sri Lanka: Census of population and housing-2001 Sri Lanka: Colombo district report. Colombo: Department of Census and statistics; 2004

28. Streiner DL, Norman GR: Health measurement scales: a practical guide to their development and use. 3rd edition. Oxford: Oxford University Press; 1995.

29. Tabachnick BG, Fidell LS: Using multivariate statistics. 2nd edition. London: Harper \& Row; 1989.

30. Brown TA: Confirmatory factor analysis for applied research. New York: Guilford; 2006

31. JöreskogK G, Sörbom D: LISREL 8: User's reference quide. Chicago, IL: Scientific Software International; 1996.

32. Chang $M$, Brown $R$, Nitzke $S$ : Scale development: factors affecting diet, exercise, and stress management (FADESM). BMC Public Health 2008, 8:76.

33. Kline RB: Principles and Practice of Structural Equation Modeling. 2nd edition. New York: The Guilford Press; 2005.

34. Popkin BM, Duffey K, Gorden-Larsen P: Environmental influences on food choice, physical activity and energy balance. Physiol Behav 2005, 86(5):603-613

35. De Bourdeaudhuij I, Sallis JF, Saelens BE: Environmental correlates of physical activity in a sample of Belgian adults. American Journal of Health Promotion 2003, 18(1):83-92.

36. McCormack GR, Masse LC, Bulsara M, Pikora TJ, Giles-Corti B: Constructing indices representing supportiveness of the physical environment for walking using the Rasch measurement model. Int I Behav Nutr Phys Activ 2006, 3:44.

37. Spittaels H, Foster C, Oppert JM, Rutter H, Oja P, Sjöström M, De Bourdeaudhui I: Assessment of environmental correlates of physical activity: development of a European questionnaire. Int I Behav Nutr Phys Activ 2009, 6:39.

38. Redding CA, Maddock JE, Rossi JS: The sequential approach to measurement of health behavior constructs: issues in selecting and developing measures. CA J Health Promot 2006, 4(1):83-101.

39. Yousefian A, Hennessy E, Umstattd RM, Economos CD, Hallam JS, Hyatt RR, Hartley D: Development of the rural active living assessment tools: measuring rural environments. Prev Med 2010, 50:S86-S92.

40. Snyder-Halpern R: Indicators of organizational readiness for clinical information technology/ systems innovation: a Delphi study. Int J Med Informat 2001, 63:179-204

41. Ogilvie D, Mitchell R, Mutrie N, Petticrew M, Platt S: Perceived characteristics of the environment associated with active travel: development and testing of a new scale. Int J Behav Nutr Phys Activ 2008, 5:32.

42. LeslieE B, Saelens BE, Frank LD, Owen N, Bauman A, Coffee N, Hugo G: Residents' perception of walkability attributes in objectively different neighbourhoods: a pilot study. Health Place 2005, 11:227-236.

43. Saelens BE, Sallis JF, Black JB, Chen D: Neighbourhood- based differences in physical activity: an environment scale evaluation. Am J Publ Health 2003, 93(9):1552-1558.

44. Rhodes RE, Courneya KS, Blanchard CM, Plotnikoff RC: Prediction of leisuretime walking: an integration of social cognitive, perceived environmental and personality factors. Int I Behav Nutr Phys Activ 2007, 4:51.

45. Handy SL, Boarnet MG, Ewing R, Killingsworth RE: How the built environment affects physical activity: views from urban planning. Am J Prev Med 2002, 23(25):64-73.

46. MacCallum RC, Widaman KF, Zhang S, Hong S: Sample size in factor analysis. Psychol Meth 1999, 4(1):84-99.

doi:10.1186/1471-2458-14-423

Cite this article as: De Silva Weliange et al.: Development and validation of a tool to assess the physical and social environment associated with physical activity among adults in Sri Lanka. BMC Public Health 2014 14:423.

\section{Submit your next manuscript to BioMed Central and take full advantage of:}

- Convenient online submission

- Thorough peer review

- No space constraints or color figure charges

- Immediate publication on acceptance

- Inclusion in PubMed, CAS, Scopus and Google Scholar

- Research which is freely available for redistribution 